\title{
Molecular Epidemiological Survey of the Babesia gibsoni cytochrome b Gene in Western Japan
}

\author{
Masato SAKUMA ${ }^{1)}$, Kenta FUKUDA ${ }^{2)}$, Katsuyoshi TAKAYAMA ${ }^{2)}$, Yukuharu KOBAYASHI ${ }^{2}$, \\ Takako SHIMOKAWA MIYAMA ${ }^{3)}$, Asuka SETOGUCHI ${ }^{1)}$ and Yasuyuki ENDO ${ }^{1) *}$ \\ ${ }^{1)}$ Laboratory of Small Animal Internal Medicine, Joint Faculty of Veterinary Medicine, Kagoshima University, 1-21-24 Korimoto, \\ Kagoshima, Kagoshima 890-0065, Japan \\ 2) ADTEC Co., Ltd., 1693-6 Yokkaichi, Usa, Oita 879-0471, Japan \\ 3) Veterinary Teaching Hospital, Kagoshima University, 1-21-24 Korimoto, Kagoshima, Kagoshima 890-0065, Japan
}

(Received 28 March 2012/Accepted 11 May 2012/Published online in J-STAGE 25 May 2012)

ABSTRACT. In this study, we conducted a survey of the cytochrome b (cytb) gene of Babesia gibsoni (B. gibsoni) isolated from clinical cases to determine the prevalence of potential atovaquone (ATV)-resistant variants. Ninety-two blood samples were collected from naturally $B$. gibsoni infected dogs. The cytb nucleotide sequence was determined by direct sequencing. Twelve non-synonymous amino acid substitutions were identified in cytb. The principal ATV-resistant substitution, M121I, was detected in three cases. This survey determined that potentially ATV-resistant B. gibsoni strains are present in dogs in Japan.

KEY WORDS: Babesia gibsoni, cytochrome $b$ gene, drug-resistance, epidemiological survey.

doi: 10.1292/jvms.12-0140; J. Vet. Med. Sci. 74(10): 1341-1344, 2012

Babesia is a tick-borne protozoan pathogen. Dogs are known to be susceptible to two species of Babesia, Babesia gibsoni (B. gibsoni) and B. canis [3-5]. In canine practice, $B$. gibsoni infection is more problematic than $B$. canis infection in Japan, because of its virulence and difficulty of treatment. Severe hemolytic anemia and thrombocytopenia are observed in dogs showing an acute onset of disease $[3,5]$. Concurrent clinical symptoms such as acute kidney failure, disseminated intravascular coagulation and secondary immune-mediated hemolytic anemia can be also observed and are often fatal $[3,5]$. In Japan, B. gibsoni infected dogs are mainly observed in the western part of Japan, although affected areas seem to expand towards the northeast $[8,9,13]$. The definitive treatment strategy for $B$. gibsoni infection has not yet been established $[3,5,10,15,16]$. Diminazene aceturate is used as a first-line drug for $B$. gibsoni infection in Japan [10]. But, it often fails to eliminate babesia from the host, and a relapse of the disease is frequently observed [10, 15]. Furthermore, diminazene aceturate has a narrow safety margin, and occasionally induces severe side effects [10]. For these reasons, there have been efforts in canine practice to establish an alternative therapeutic strategy against $B$. gibsoni infection.

Recent studies by us and others have shown that atovaquone (ATV), an analogue of ubiquinone and one of the anti-plasmodium drugs, can be useful and effective for dogs showing an acute onset of babesiosis caused by B. gibsoni, and results in rapid improvements in clinical symptoms

\footnotetext{
*Correspondence to: Endo, Y., Laboratory of Small Animal Internal Medicine, Joint Faculty of Veterinary Medicine, Kagoshima University, 1-21-24 Korimoto, Kagoshima 890-0065, Japan. e-mail: k5155981@kadai.jp

(C)2012 The Japanese Society of Veterinary Science
}

without any adverse effects $[2,11,14]$. However, we found that approximately $60 \%$ of ATV-treated dogs experienced a relapse of the disease [14]. Furthermore, DNA sequencing of the $B$. gibsoni cytochrome $b$ (cytb) gene, presumed as an ATV binding site, revealed that the gene from the relapsed cases had different nucleotide sequences [14]. One of them will be a substitution for ATV-resistance, resulting in M121I amino acid (AA) substitution as previously reported [7, 12]. Surprisingly, B. gibsoni with M121I was dominant in one case, even at the primary onset of disease [14]. At present, many veterinarians have started to use ATV for clinical cases of babesiosis, and ATV has become commercially available, even in Japan. Therefore, it is important to know the prevalence of possible drug-resistant variants in the environment. In the present study, a molecular epidemiological survey of the $B$. gibsoni $c y t b$ gene was carried out to investigate its polymorphism and the prevalence of possibly ATV-resistant B. gibsoni variants in Japan.

Ninety-two blood samples were collected from dogs naturally infected with B. gibsoni during 2007 to 2011 . Of them, 78 cases were kindly provided by a commercial laboratory (ADTEC Co., Ltd., Oita, Japan). These 78 samples were collected from clinically suspicious cases and were confirmed to be positive for $B$. gibsoni infection by following $B$. gibsoni p 18 rRNA gene PCR. Remaining 14 samples were collected from clinical cases diagnosed at the Kagoshima University Veterinary Teaching Hospital (KUVTH) by blood examination and p18 rRNA gene PCR. Samples from the commercial laboratory were collected from dogs in areas west of the Kanto plain of Japan (Tokyo, Shizuoka, Kyoto, Nara, Osaka, Hyogo, Okayama, Hiroshima, Kagawa, Kochi, Yamaguchi, Fukuoka, Saga, Nagasaki, Kumamoto, Miyazaki, Kagoshima and Okinawa Prefectures) that had not been treated with any anti-protozoal drugs including ATV. Samples obtained at KUVTH 
Table 1. The frequency of nucleotide and deduced AA substitutions in the B. gibsoni cytb gene

\begin{tabular}{|c|c|c|c|}
\hline \multicolumn{3}{|c|}{ Substitutions } & \multirow{2}{*}{ Frequency $(\%)$} \\
\hline Site & Nucleotide & Amino acid & \\
\hline nt 94 & $\mathrm{CTG}>\mathrm{CTA}$ & - & $16 / 92(18.0 \%)$ \\
\hline nt 102 & $\mathrm{CTA}>\mathrm{CTG}$ & - & $4 / 92(4.5 \%)$ \\
\hline nt 127 & ATG $>$ GTG & M43V & $1 / 92(1.1 \%)$ \\
\hline nt 129 & ATG $>$ ATT & M43I & $1 / 92(1.1 \%)$ \\
\hline nt 201 & $\mathrm{GCT}>\mathrm{GCC}$ & - & 7/92 (7.9\%) \\
\hline nt 207 & $\mathrm{TGT}>\mathrm{TGC}$ & - & $4 / 92(4.5 \%)$ \\
\hline nt 240 & $\mathrm{CAT}>\mathrm{CAC}$ & - & $1 / 92(1.1 \%)$ \\
\hline nt 267 & AGT $>$ AGC & - & $1 / 92(1.1 \%)$ \\
\hline nt 322 & $\mathrm{GCT}>\mathrm{ACT}$ & $\mathrm{A} 108 \mathrm{~T}$ & $2 / 92(2.2 \%)$ \\
\hline nt 363 & ATG $>$ ATA & M121I & $3 / 92(3.3 \%)$ \\
\hline nt 378 & $\mathrm{GCA}>\mathrm{GCG}$ & - & $4 / 92(4.5 \%)$ \\
\hline nt 393 & $\mathrm{AAC}>\mathrm{AAT}$ & - & $4 / 92(4.5 \%)$ \\
\hline nt 406 & $\mathrm{GGA}>\mathrm{GGG}$ & $\mathrm{I} 136 \mathrm{~V}$ & $1 / 92(1.1 \%)$ \\
\hline nt 423 & $\mathrm{ATT}>\mathrm{ATC}$ & - & $4 / 92(4.5 \%)$ \\
\hline nt 430 & $\mathrm{TAC}>\mathrm{TAT}$ & - & $2 / 92(2.2 \%)$ \\
\hline nt 456 & $\mathrm{CCA}>\mathrm{CCG}$ & - & $11 / 92(12.4 \%)$ \\
\hline nt 492 & $\mathrm{TTA}>\mathrm{TTG}$ & - & $5 / 92(5.6 \%)$ \\
\hline nt 535 & $\mathrm{ATC}>\mathrm{ATT}$ & - & $5 / 92(5.6 \%)$ \\
\hline nt 558 & $\mathrm{AAT}>\mathrm{AAC}$ & - & $14 / 92(15.7 \%)$ \\
\hline nt 588 & GTA $>$ GTG & - & $4 / 92(4.5 \%)$ \\
\hline nt 640 & $\mathrm{TGC}>\mathrm{TGT}$ & - & $4 / 92(4.5 \%)$ \\
\hline nt 648 & $\mathrm{GCT}>\mathrm{ACT}$ & $\mathrm{A} 216 \mathrm{~T}$ & $1 / 92(1.1 \%)$ \\
\hline nt 658 & GTT $>$ ATT & V220I & $6 / 92(6.5 \%)$ \\
\hline nt 676 & ATA $>$ GTA & $\mathrm{I} 226 \mathrm{~V}$ & $11 / 92(12.0 \%)$ \\
\hline nt 726 & $\mathrm{CCA}>\mathrm{CCG}$ & - & $8 / 92(9.0 \%)$ \\
\hline nt 810 & $\mathrm{GCA}>\mathrm{GCT}$ & - & $4 / 92(4.5 \%)$ \\
\hline nt 827 & $\mathrm{GGC}>\mathrm{GGT}$ & $\mathrm{A} 276 \mathrm{~V}$ & $1 / 92(1.1 \%)$ \\
\hline nt 829 & $\mathrm{GCA}>\mathrm{CCA}$ & - & $1 / 92(1.1 \%)$ \\
\hline nt 832 & $\mathrm{CAT}>\mathrm{CAC}$ & - & $1 / 92(1.1 \%)$ \\
\hline nt 835 & $\mathrm{CAT}>\mathrm{CAC}$ & - & $5 / 92(5.6 \%)$ \\
\hline nt 869 & AGC $>$ AGT & A290V & $1 / 92(1.1 \%)$ \\
\hline nt 907 & ATA $>$ GTA & $\mathrm{I} 303 \mathrm{~V}$ & $7 / 92(7.6 \%)$ \\
\hline nt 928 & $\mathrm{CCT}>\mathrm{TCT}$ & P310S & $15 / 92(16.3 \%)$ \\
\hline nt 948 & $\mathrm{TAT}>\mathrm{TAC}$ & - & $1 / 92(1.1 \%)$ \\
\hline nt 952 & $\mathrm{TAC}>\mathrm{TAT}$ & - & $4 / 92(4.5 \%)$ \\
\hline nt 984 & $\mathrm{GAT}>\mathrm{GAC}$ & - & $4 / 92(4.5 \%)$ \\
\hline nt 1002 & $\mathrm{GGT}>\mathrm{GGC}$ & - & $1 / 92(1.1 \%)$ \\
\hline nt 1042 & $\mathrm{CTA}>\mathrm{TTA}$ & - & $1 / 92(1.1 \%)$ \\
\hline nt 1068 & $\mathrm{TTA}>\mathrm{TTG}$ & - & $2 / 92(2.2 \%)$ \\
\hline
\end{tabular}

were collected from dogs with no treatment history during the first visit. Total DNA was isolated from whole blood using a DNA extraction kit (DNA blood mini kit, QIAGEN, Hilden, Germany) and used for the following PCR analyses as a template. These samples were confirmed to be positive for GAPDH gene amplification as an internal control and for B. gibsoni p 18 rRNA gene by PCR analyses $[1,6]$. Nested PCRs were carried out for amplification of the B. gibsoni $c y t b$ gene, and the nucleotide sequence was determined by direct sequencing by the methods previously described [14]. GENETYX Version 11.0 software (Software Development Co., Ltd., Tokyo, Japan) was used to characterize the obtained nucleotide sequence data. Then, the prevalence of nucleotide and amino acid (AA) substitutions was evaluated.

Compared with the standard sequence of the $B$. gibsoni cytb gene (DDBJ/GenBank/EMBL accession number, AB215096), 39 sites with nucleotide substitutions were detected in B. gibsoni isolated from 92 cases. Most were induced synonymous AA substitutions; however, 12 types were induced non-synonymous AA substitutions (Table 1). Nucleotide substitutions resulting in AA substitutions A108T, M121I, V220I, I226V, I303V and P310S were observed in multiple cases, while other types were detected in single case each. B. gibsoni possessing CYTB with M121I substitution, a major candidate responsible for the ATV-resistant phenotype, was found in 3 cases $(3.3 \%)$ [7, 12]. The other types of substitutions, V220I and I303V, related to ATV-resistance as reported by Matsuu et al. were also detected in $6(6.5 \%)$ and 7 cases $(7.6 \%)$, respectively [12].

Figure 1 shows the geographical distribution of dogs with $B$. gibsoni that showed nucleotide substitutions in $c y t b$, resulting in AA substitutions. The isolates with $\mathrm{I} 226 \mathrm{~V}$ and P310S were mainly distributed in south Kyushu and Okinawa, respectively. Three cases with M121I were found in Fukuoka, Kagoshima and Okinawa; however, no specific distribution pattern was observed in this type of $B$. gibsoni. Other candidates related to ATV-resistance, B. gibsoni with V220I and/or I303V, were mainly detected in the Kansai area.

To our knowledge, this is the first molecular epidemiological report concerning the $c y t b$ gene of $B$. gibsoni. This survey clarified that there have already been several variants of the B. gibsoni cytb gene, and suggested that some genotypes were related to regionality. Most of the polymorphisms were different from substitutions including M121I, V220I or I303V, which have been suggested to be correlated with ATV-resistance [12]. However, it is noteworthy that the ATV-resistant variants with M121I, V220I or I303V were dominant in some cases. Our findings suggest that $B$. gibsoni with ATV-resistance has already been existing in nature. Although its prevalence is not high, it would be a threat in the future with use of ATV for canine babesiosis. The results obtained in this survey might be a contraindication for future use of ATV.

In this study, although we found multiple cases infected with B. gibsoni possessing V220I, I226V, I303V or P310S $c y t b$, these AA substitutions might not contribute to the development of an ATV-resistant phenotype in clinical cases. Our previous study revealed that clinical cases that were treated with ATV showed a good response against the treatment, even though $B$. gibsoni with those AA substitutions was dominant [14]. Furthermore, a recent study showed that the major candidate responsible for ATV-resistance is M121I [7]. However, a further evaluation, especially of V220I and $\mathrm{I} 303 \mathrm{~V}$, is necessary to clarify the relationship between substitutions in $c y t b$ and ATV-resistance. At present, it is likely that M121I is the most important AA substitution in $c y t b$ for the development of ATV-resistance [7, 12, 14].

We found three cases whose dominant B. gibsoni were M121I type $c y t b$. As mentioned above, the prevalence was low $(3.3 \%)$. However, we have to allow for the limitations 


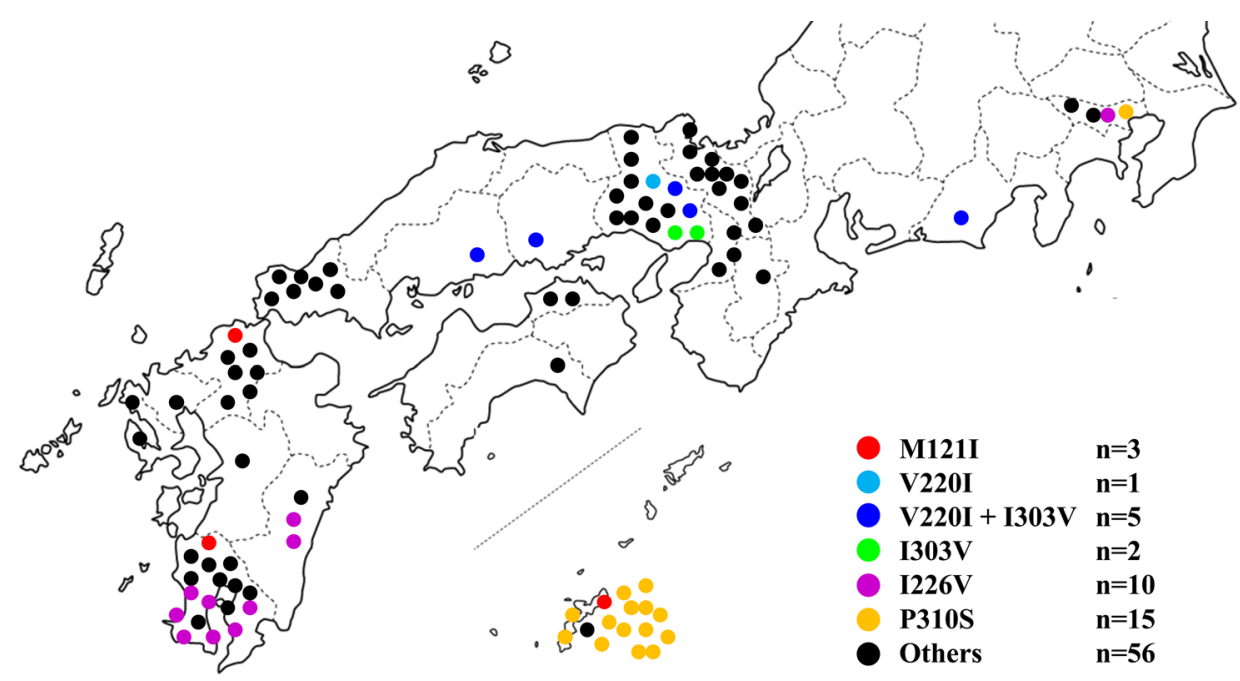

Fig. 1. Geographical distribution of B. gibsoni based on CYTB AA sequences. Each dot represents one case.

of this study and a possible underestimation of the true prevalence. We simply retrospectively evaluated the $c y t b$ genotypes of B. gibsoni in infected dogs. Therefore, we do not know whether the dogs infected with variant $c y t b$ types of $B$. gibsoni actually show resistance against ATV treatment or not. In addition, we have to consider the possibility that a minor population of such genotypes might have been missed in our analysis, because the population of $B$. gibsoni may have been too crude, and a dominant genotype of $B$. gibsoni should have been selectively amplified in the PCR analysis [14].

The findings obtained in this study provide useful baseline data concerning the prevalence of several genotypes of $B$. gibsoni in Japan. An additional large-scale epidemiological survey of the B. gibsoni cytb gene with a larger number of samples might be required in the future. Furthermore, studies on the population of ticks with $B$. gibsoni and the relationships between $c y t b$ genotypes and clinical outcomes would be also necessary.

ACKNOWLEDGMENTS. This study was supported with grants from the Ministry of Education, Culture, Sports, Science and Technology, and from the Japan Society for the Promotion of Science

\section{REFERENCES}

1. Birkenheuer, A. J., Levy, M. G. and Breitschwerdt, E. B. 2003. Development and evaluation of a seminested PCR for detection and differentiation of Babesia gibsoni (Asian genotype) and B. canis DNA in canine blood sample. J. Clin. Microbiol. 41: 4172-4177. [Medline] [CrossRef]

2. Birkenheuer, A. J., Levy, M. G. and Breitschwerdt, E. B. 2004. Efficacy of combined atovaquone and azithromycin for therapy of chronic Babesia gibsoni (Asian genotype) infections in dogs. J. Vet. Intern. Med. 18: 494-498. [Medline] [CrossRef]

3. Boozer, A. L. and Macintire, D. K. 2003. Canine babesiosis.
Vet. Clin. North Am. Small Anim. Pract. 33: 885-904. [Medline] [CrossRef]

4. Boustani, M. R. and Gelfand, J. A. 1996. Babesiosis. Clin. Infect. Dis. 22: 611-615. [Medline] [CrossRef]

5. Farwell, G. E., LeGrand, E. K. and Cobb, C. C. 1982. Clinical observations on Babesia gibsoni and Babesia canis infection in dogs. J. Am. Vet. Med. Assoc. 80: 507-511.

6. Fukumoto, S., Xuan, X., Shigeno, S., Kimbita, E., Igarashi, I., Nagasawa, H., Fujisaki, K. and Mikami, T. 2001. Development of a polymerase chain reaction method for diagnosing Babesia gibsoni infection in dogs. J. Vet. Med. Sci. 63: 977-981. [Medline] [CrossRef]

7. Iguchi, A., Matsuu, A., Ikadai, H., Hasanuzzaman Talukder, M. and Hikasa, Y. 2012. Development of in vitro atovaquone-resistant Babesia gibsoni with a single-nucleotide polymorphism in cytb. Vet. Parasitol. 185: 145-150. [Medline] [CrossRef]

8. Inokuma, H., Yamamoto, S. and Morita, C. 1998. Survey of tickborne diseases in dogs infested with Rhipicephalus sanguineus at a kennel in Okayama Prefecture, Japan. J. Vet. Med. Sci. 60: 761-763. [Medline] [CrossRef]

9. Inokuma, H., Yoshizaki, Y., Shimada, Y., Sakata, Y., Okuda, M. and Onishi, T. 2003. Epidemiological survey of Babesia species in Japan performed with specimens from ticks collected from dogs and detection of new Babesia DNA closely related to $B a$ besia odocoilei and Babesia divergens DNA. J. Clin. Microbiol. 41: 3494-3498. [Medline] [CrossRef]

10. Itoh, N., Higuchi, S. and Kawamura, S. 1988. The effect of diminazene aceturate on splenonectomized dogs with Babesia gibsoni infection. Vet. Clin. Pathol. 17: 94-98. [Medline] [CrossRef]

11. Matsuu, A., Koshida, Y., Kawahara, M., Inoue, K., Ikadai, H., Hikasa, Y., Okano, S. and Higuchi, S. 2004. Efficacy of atovaquone against Babesia gibsoni in vivo and in vitro. Vet. Parasitol. 124: 9-18. [Medline] [CrossRef]

12. Matsuu, A., Miyamoto, K., Ikadai, H., Okano, S. and Higuchi, S. 2006. Cloning of the Babesia gibsoni cytochrome b gene and isolation of three single nucleotide polymorphisms from parasites present after atovaquone treatment. Am. J. Trop. Med. Hyg. 74: 593-597. [Medline]

13. Miyama, T., Sakata, Y., Shimada, Y., Ogino, S., Watanabe, M., 
Itamoto, K., Okuda, M., Verdida, R. A., Xuan, X., Nagasawa, H. and Inokuma, H. 2005. Epidemiological survey of Babesia gibsoni infection in dogs in eastern Japan. J. Vet. Med. Sci. 67: 467-471. [Medline] [CrossRef]

14. Sakuma, M., Setoguchi, A. and Endo, Y. 2009. Possible emergence of drug-resistant variants of Babesia gibsoni in clinical cases treated with atovaquone and azithromycin. J. Vet. Intern. Med. 23: 493-498. [Medline] [CrossRef]

15. Suzuki, K., Wakabayashi, H., Takahashi, M., Fukushima, K.,
Yabuki, A. and Endo, Y. 2007. A possible treatment strategy and clinical factors to estimate the treatment response in Babesia gibsoni infection. J. Vet. Med. Sci. 69: 563-568. [Medline] [CrossRef]

16. Wulansari, R., Wijaya, A., Ano, H., Horii, Y. and Makimura, S. 2003. Lymphocyte subsets and specific IgG antibody levels in clindamycin-treated and untreated dogs experimentally infected with Babesia gibsoni. J. Vet. Med. Sci. 65: 579-584. [Medline] [CrossRef] 